\title{
CUANTIFICACIÓN VOLTAMÉTRICA DE PLOMO Y CADMIO EN PAPA FRESCA
}

\section{VOLTAMMETRIC QUANTIFICATION OF LEAD AND CADMIUM IN FRESH POTATO}

\author{
Yuri Lorena Moreno Mariño ${ }^{1}$, José Mauricio García Colmenares ${ }^{2}$, Sandra Patricia Chaparro Acuña ${ }^{3}$
}

\begin{abstract}
${ }^{1}$ Químico de Alimentos, Estudiante M.Sc. en Química, Facultad de Ciencias. Universidad Pedagógica y Tecnológica de Colombia, Avenida Central del Norte 39-115, Tunja-Boyacá, Colombia, e-mail: yuri.moreno@uptc.edu.co; ${ }^{2}$ Químico de Alimentos, Investigador Grupo de Investigación en Química Ambiental, Facultad de Ciencias. Universidad Pedagógica y Tecnológica de Colombia, e-mail: josemauricio.garcia@uptc.edu.co; ${ }^{3}$ Químico de Alimentos, Especialista y Magister en Ciencia y Tecnología de los Alimentos, Profesor Asistente, Escuela de Ciencias Químicas, Facultad de Ciencias. Universidad Pedagógica y Tecnológica de Colombia. Grupo de Investigación en Química Ambiental, e-mail: patricia.chaparro@uptc.edu.co
\end{abstract}

Rev. U.D.C.A Act. \& Div. Cient. 19(1): 97-104, Enero-Junio, 2016

\section{RESUMEN}

La presencia de metales pesados en alimentos ha sido reportada como uno de los problemas de alto impacto, debido a su toxicidad y afecciones en la salud humana. El método voltametría de onda cuadrada (VOC) fue validado para la cuantificación de cadmio y de plomo en tubérculos de papa fresca. Este estudio, se realizó usando: como buffer, solución Britton-Robinson (B-R, pH 4,8); carbono vítreo, como electrodo de trabajo; $\mathrm{Ag} / \mathrm{AgCl}$, como electrodo de referencia y platino, como electrodo auxiliar. La aplicación de la técnica VOC fue realizada en tubérculos recolectados en la central de abastos de Tunja-Boyacá, Colombia. El análisis de varianza de la validación no presentó diferencia estadística; el análisis fue realizado con un nivel de confiabilidad de $94,5 \%$, para cadmio y 92,0\%, para plomo. La concentración de estos metales en las muestras analizadas estuvieron entre un rango de 0,111 a 0,304ppm, que sobrepasa los límites máximos establecidos por las normas nacionales e internacionales, vigentes para papa de consumo humano.

Palabras clave: Electroquímica, electrodo de carbono vítreo, metales pesados, tubérculo.

\section{SUMMARY}

The presence of heavy metals in food has been reported as one of the high impact problems due to their toxicity and human health problems. The square wave voltammetry method (VOC) was validated for quantification of cadmium and lead in potato. This study was conducted using as buffer solution Britton-Robinson (BR, pH 4.8), glassy carbon as working electrode, $\mathrm{Ag} / \mathrm{AgCl}$ as reference electrode and platinum as counter electrode. The application of VOC technique was performed in tubers from the central supply of Tunja (Boyacá-Colombia). The analysis of variance showed no statistical difference validation, analysis was performed with a confidence level of $94.5 \%$ to $92.0 \%$ for cadmium and lead. The concentration of these metals in the samples analyzed were within the range of 0.111 to $0.304 \mathrm{ppm}$ exceeding the limits set by national and international standards for tubers of human consumption.

Key words: Electrochemistry, glassy carbon electrode, heavy metals, tuber.

\section{INTRODUCCIÓN}

En los últimos años, la producción nacional de papa se ha incrementado en un 3,4\%, paralelo a su nivel de rendimiento agronómico, situación de la cadena productiva, donde el departamento de Boyacá se ubica en un segundo lugar en Colombia (Barrientos et al. 2014; IICA, 1999). Tales logros, involucran prácticas agrícolas con amplio uso de agroquímicos y, en algunos casos, descontrolada dosificación. Las aplicaciones sucesivas de productos agrícolas que contienen impurezas de metales pesados, como zinc, manganeso, plomo y cadmio y la exposición por parte de suelos y ambientes agrícolas a contaminantes provenientes de la explotación y la refinación de metales, conllevan a la formación de depósitos y de residuos, en los alimentos cosechados en las zonas expuestas a los desequilibrios ambientales, involucrados en estas acciones (Huang et al. 2014; Gebrekidan et al. 2013). Alimentos agrícolas, como el tomate, la papa, la espinaca y la lechuga son reconocidos bioindicadores ambientales, debido a su capacidad de retención e incorporación de com- 
puestos durante su crecimiento, reflejando la presencia de los mismos, por alteraciones fenotípicas (Kabata, 2000).

Los metales pesados son sustancias no degradables, por tanto, se consideran contaminantes estables y persistentes, al ser depositados al medio ambiente. Esto ocasiona alteraciones en los diferentes ecosistemas, llegando a reducir la calidad de vida de los seres vivos (Madero \& Marrugo, 2011). Los metales, como plomo $(\mathrm{Pb})$ y cadmio $(\mathrm{Cd})$ deben su toxicidad a la fuerte afinidad de sus cationes hacia el átomo de azufre y, por ende, hacia los grupos sulfhidrilo (-SH), los cuales, están presentes, comúnmente, en las enzimas que participan en las reacciones metabólicas de los organismos acuáticos y terrestres. Los metales pesados pueden entrar en el cuerpo humano, a través de la cadena alimenticia, llevando a un incremento de enfermedades crónicas, como deformidades y cáncer (Chang et al. 2014). Se ha demostrado que el consumo de frutas y de vegetales es el primer paso de la exposición del hombre a los metales pesados, por lo que es de vital importancia evaluar el contenido de estos elementos en los alimentos, como la papa. El plomo, en el organismo humano, puede causar lesiones al sistema urinario, nervioso, reproductor, inmunológico (Yucra et al. 2008), cardiovascular y gastrointestinal (FAO, 2004). El Codex Alimentarius (FAO, 2014) reporta un límite máximo para plomo y cadmio de $0,1 \mathrm{mg} / \mathrm{kg}$, en tubérculo y la Unión Europea, para la papa pelada, un límite de a $0,1 \mathrm{mg} / \mathrm{kg}$, peso fresco de plomo y de cadmio (Unión Europea, 2014). El Codex Alimentarius estableció una Ingesta Mensual Tolerable Provisional de 25 $\mu$ g/ $\mathrm{kg}$ de peso corporal para cada uno de estos elementos y destaca que el plomo está asociado con una disminución de al menos tres puntos del cociente de inteligencia, en los niños y un aumento en la presión arterial, en los adultos. En Colombia, el Ministerio de Salud y Protección Social (2013), en la Resolución 4506 de 2013, estableció un límite máximo para plomo y para cadmio de $0,1 \mathrm{mg} / \mathrm{kg}$ peso fresco en papa pelada.

Los métodos típicos para el análisis simultáneo de metales son la espectrometría de masas con plasma de acoplamiento inductivo- (ICP-MS), espectrometría de fluorescencia de rayos X y espectrometría de absorción atómica (Behrooz et al. 2009; Klamtet et al. 2007; Isha et al. 2007); sin embargo, el análisis implica instrumentos sofisticados y mantenimiento e insumos de alto costo. Por el contrario, el método electroquímico es una de las técnicas más favorables para la determinación de contaminantes del medio ambiente, ya que es un ensayo no destructivo, de fácil operatividad y puede alcanzar una mayor sensibilidad (Rosolina et al. 2015; Guzinski et al. 2013; Segura, 2003; Jakumnee et al. 2001). Entre los diferentes métodos electroquímicos, la voltametría de onda cuadrada (VOC) ha demostrado ser un método sencillo y eficaz para la determinación de iones de metales pesados (Mhammedi et al. 2010).
En el presente estudio, se validaron los métodos voltamétricos para la determinación de plomo y de cadmio en papa cruda, recolectada en la central de abastos del sur de Tunja, permitiendo el diagnóstico del grado de inocuidad, según la Unión Europea y el Codex Alimentarius del producto, ofrecido en este principal espacio de acopio regional.

\section{MATERIALES Y MÉTODOS}

Reactivos: Todos los reactivos usados fueron de grado analítico: hidróxido de sodio Panreac, 99\% de pureza; ácido acético JT Baker, 99,8\%; ácido bórico JT Baker, 99\%; ácido fosfórico Panreac, $85 \%$ de pureza; nitrato de plomo JT Baker, $99 \%$ de pureza; nitrato de cadmio Panreac, 99\% de pureza; ácido nítrico Panreac, 65\% de pureza; cloruro de sodio, 99\%; JT Baker, $99 \%$ de pureza y soluciones patrón de 1000ppm de cadmio y plomo JT Baker, $99 \%$ de pureza. Todas las soluciones se prepararon con agua desionizada Sistema Milli-Di ${ }^{\mathrm{TM}}$ y Simplicity con conductividad menor a 0,05uS.

Equipos: Se verificaron las condiciones óptimas de funcionamiento y de calibración de los equipos, necesarios para la validación del método, dentro de los que se encuentran polarógrafo BAS CV 50W, equipado con un analizador voltamperométrico; electrodo de trabajo de carbón vítreo BASI MF-2070; electrodo de referencia Ag/AgCl BASI MF-2052 y un electrodo auxiliar de platino BASI MW-1032; balanza analítica Aventure Ohaus y pH-metro Sartorius Scohott CG842. La comparación de resultados de voltametría de onda cuadrada frente al método espectrofotométrico por absorción atómica, se realizó en espectrofotómetro de llama de acetileno-aire (Marca Shimadzu), con previa digestión húmeda de la muestra, según método SM 3111B y SM 3030E.

Soluciones de trabajo: A partir de soluciones stock de plomo y de cadmio (JT Baker, 99\% de pureza y Panreac, 99\% de pureza), se prepararon dos soluciones estándar 100ppm y $1 \mathrm{ppm}$.

Electrolito de soporte (buffer Britton Robinson): Se adicionó a un balón de $100 \mathrm{~mL}, 0,618 \mathrm{~g}$ de ácido bórico, 0,56mL de ácido acético y $0,48 \mathrm{~mL}$ de ácido orto fosfórico, se ajustó a $\mathrm{pH}$ 5, con $\mathrm{NaOH} 0,1 \mathrm{~N}$ y se aforó con agua desionizada.

Parámetros voltamétricos: Se optimizaron las condiciones del análisis voltamétrico, tales como tiempo de desoxigenación, tiempo de quietud, rango de trabajo, sensibilidad, amplitud de onda y frecuencia de onda, mediante análisis por triplicado.

Respuesta señal del sistema electroquímico: Se realizó verificación del blanco, seleccionado agua desionizada y buffer relación de volumen $1: 1$, mediante barrido exploratorio, en un rango de -800 a $-200 \mathrm{mV}$ por voltametría cíclica; el vol- 
tagrama del blanco no presentó señal que pueda interferir en la identificación de los analitos e indica que el medio de análisis favoreció las condiciones de reversibilidad para las reacciones de reducción, sobre el electrodo de trabajo. Con el rango de potencial seleccionado, se analizó un blanco (Figura 1a) y un estándar de cadmio y de plomo para confirmar el potencial de onda media de los analitos; los metales presentaron señales de reducción de -584 y $-395 \mathrm{mV}$, respectivamente (Figura 1b), cercanos a los reportados por Rosolina et al. (2015); Rutyna \& Korolczuk (2014) y AOAC (1990).
Optimización de condiciones instrumentales: Los parámetros optimizados, se seleccionaron con base en la obtención de una alta señal instrumental y una onda limpia; se registró con $10 \mu \mathrm{A} / \mathrm{V}$ de sensibilidad, $20 \mathrm{mV}$ de amplitud de la onda, $15 \mathrm{~Hz}$ frecuencia, $-800 \mathrm{mV}$ a $-200 \mathrm{mV}$ de un rango de potencial. Las demás condiciones instrumentales fueron $5 \mathrm{~min}$ de desoxigenación y 5seg de tiempo de quietud.

Validación de la técnica voltamétrica: Se llevó a cabo la linealidad del método (de 0,05 a 3,000mg/L) y se determinaron
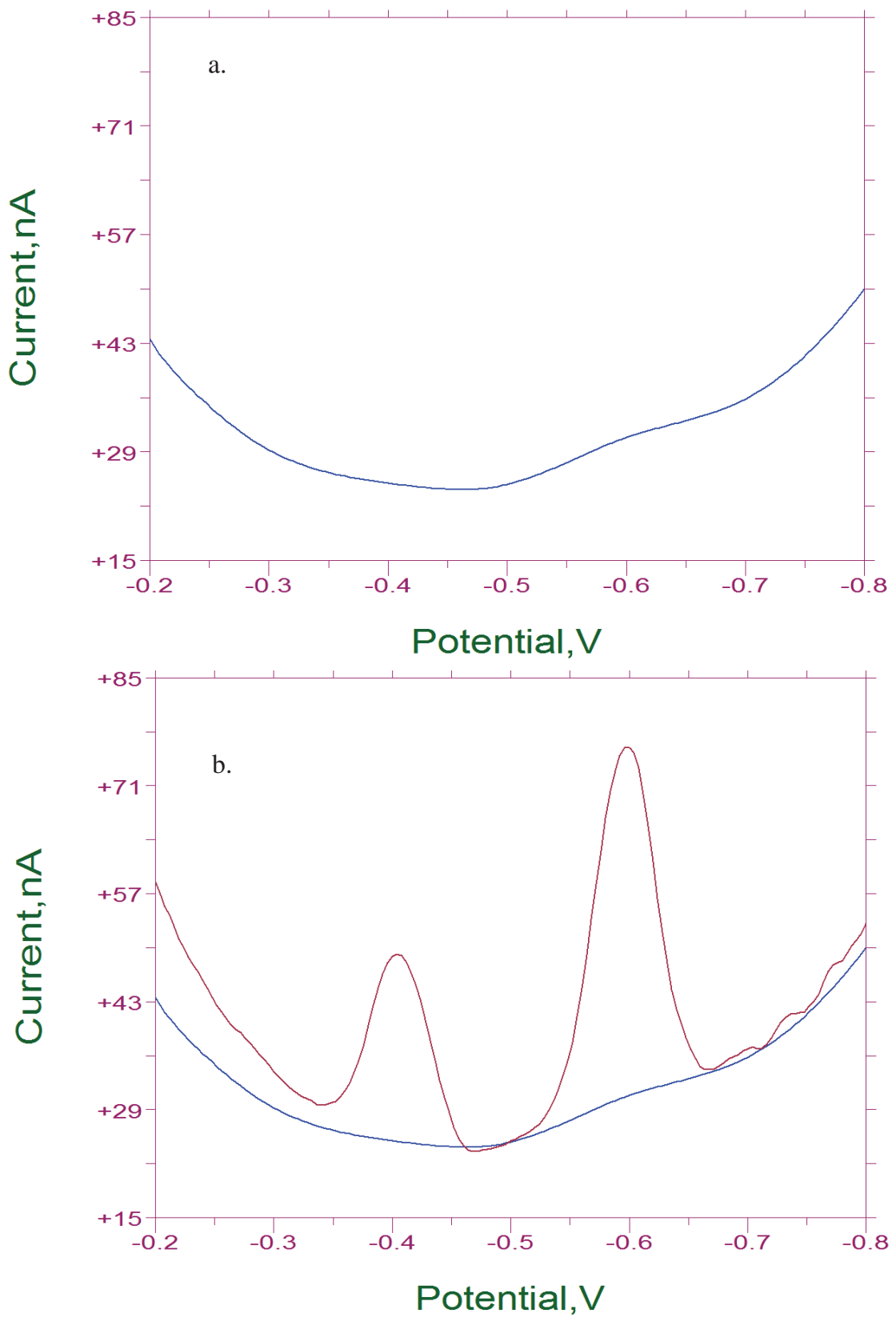

Figura 1. Voltagramas obtenidos en la técnica VOC. a) Blanco analítico y b) Estándar de plomo y de cadmio. 
los principales atributos de validación, como límite de detección (LD), límite de cuantificación (LC), precisión (desviación estándar y coeficiente de variación CV), exactitud (porcentaje de recuperación), rango útil, sensibilidad e incertidumbre (Eurachem, 2005). Para la validación, se evaluaron seis lotes de soluciones, compuestas por un blanco, un estándar alto $(2,7 \mathrm{mg} / \mathrm{L})$, un estándar bajo $(0,5 \mathrm{mg} / \mathrm{L})$, dos muestras naturales (papa) y una muestra fortificada con un estándar alto y bajo $(2,7 \mathrm{mg} / \mathrm{L}$ y $0,5 \mathrm{mg} / \mathrm{L})$, llevando a cabo el estudio dos analistas.

Muestreo y pretratamiento de la muestra: Se tomaron 4 muestras mensuales, una cada semana, en la jornada de mayor comercialización de papa (los viernes), principalmente, de las variedades Diacol Capiro, Ica Unica, Betina y Pastusa Suprema, en la central de abastos de Tunja, durante siete meses (marzo a septiembre de 2014). La papa, se recolectó al azar en los diferentes expendios hasta lograr una muestra representativa de $5 \mathrm{~kg}$ y en el laboratorio, se tomó una porción aleatoria de $1 \mathrm{~kg}$, para ser analizada. El material fresco, se cortó en rodajas, se deshidrató a $105^{\circ} \mathrm{C}$ por $6 \mathrm{~h}$, en la estufa marca $M L W$; el residuo $( \pm 200 \mathrm{~g})$, se calcinó a $500^{\circ} \mathrm{C}$ por $6 \mathrm{~h}$, en la mufla marca Termo Scientific y, finalmente, se sometió a un proceso de digestión, con $2 \mathrm{~mL}$ de ácido nítrico concentrado, hasta la obtención de cenizas blancas, que se diluyeron en el mismo reactivo, hasta un volumen final de 50mL (AOAC, 1990).

Cuantificación de plomo y cadmio en las muestras: Se llevó a cabo por el método de adición estándar. Se trasladó a la celda electroquímica una mezcla de $3 \mathrm{~mL}$ de muestra y $4 \mathrm{~mL}$ de la solución electrolítica y posterior adición de $70 \mu \mathrm{L}$ de solución estándar de 1ppm de cadmio y de plomo.
Diseño experimental: La validación, se evaluó a través de un diseño factorial completamente al azar $2^{6}$; las muestras, se analizaron al azar por triplicado; en total, 64 ensayos, con dos analistas. Las diferencias estadísticas, se determinaron mediante un análisis de varianza, utilizando el software estadístico SPSS 18 para Windows.

\section{RESULTADOS Y DISCUSIÓN}

Curva de calibración: La curva, se construyó en un rango de concentración de 0,005 a 3,000mg/L para ambos analitos (Figura 2), obteniendo coeficientes de correlación de 0,9967 y 0,9943 , para plomo y para cadmio, respectivamente. Los anteriores resultados evidencian que existe una relación lineal alta entre la intensidad de corriente y la concentración de los analitos e, indica, que el método puede ser empleado en la cuantificación de estos metales. El valor del coeficiente de correlación está dentro de los criterios de aceptación de la guía de validación de Ministerio de Salud (2011).

Atributos del método: Los atributos del método de cuantificación de plomo y de cadmio por voltametría de onda cuadrada, se presentan en la tabla 1, encontrándose que el método posee mayor sensibilidad para la cuantificación de plomo; en contraste, la exactitud y la precisión son próximas a los criterios de aceptación de la guía de validación de Ministerio de Salud (2011). El cadmio muestra una mayor exactitud en un rango de concentración alto (113\%), mientras que el plomo, en un rango bajo (115\%); sin embargo, este parámetro en los dos métodos validados está por encima del $80 \%$ y la precisión es alta (CV menor del 5\%). Los límites de detección y de cuantificación están dentro de los resultados obtenidos en otras investigaciones (Wang et al. 2016; Yavuz et al. 2016; Wang et al. 2015).

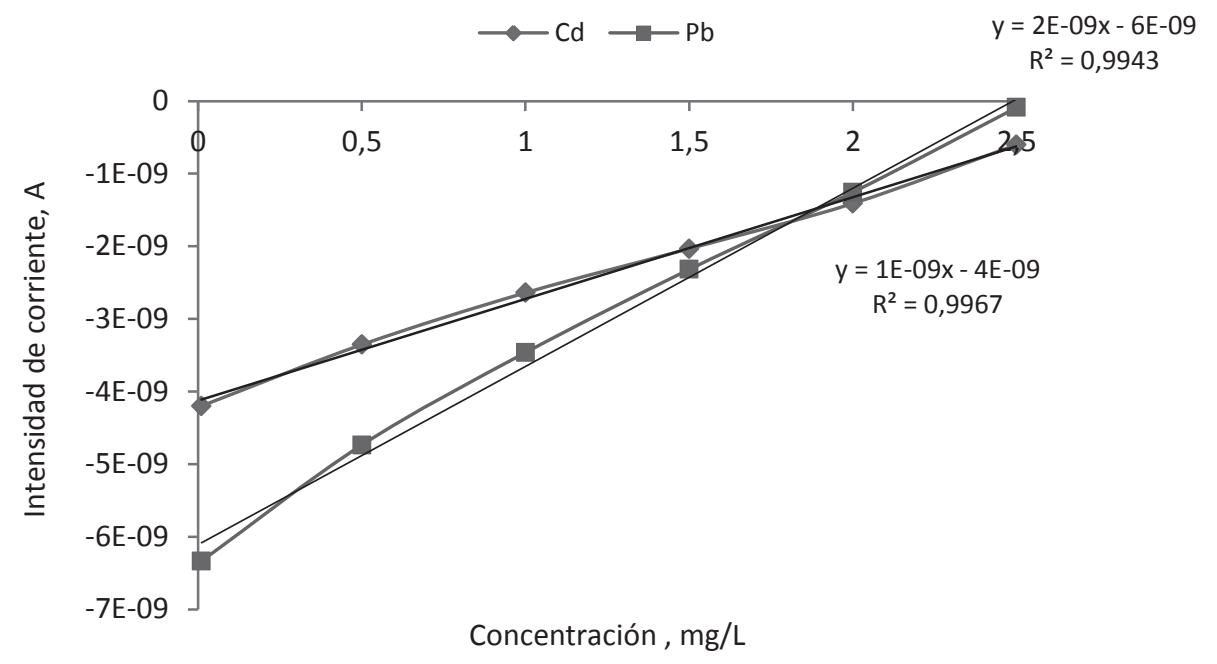

Figura 2. Curva de calibración de plomo y de cadmio. 
En cuanto a la reproducibilidad de la señal instrumental de las muestras fortificadas, se determinó que las intensidades de corriente de la muestra enriquecida con estándar en los seis ensayos realizados por los dos analistas, no presentaron variaciones estadísticas, de acuerdo al análisis de varianza de dos factores con varias muestras por grupo del paquete estadístico. Las contramuestras analizadas, mediante espectrofotometría de absorción atómica, no presentaron diferencias estadísticas $(\mathrm{P}<0,05)$, en el contenido de plomo y de cadmio. La concentración de $\mathrm{Pb}$ de $0,0220 \pm 0,0011 \mu \mathrm{g} / \mathrm{g}$ obtenida por voltametría es próxima a la obtenida por AAS, que fue de $0,0154 \pm 0,0841 \mu \mathrm{g} / \mathrm{g}$. La concentración de Cd hallada por voltametría es de $0,0064 \pm 0,0009 \mu \mathrm{g} / \mathrm{g}$, mientras que el obtenido por AAS fue de 0,0010 $\pm 0,0841 \mu \mathrm{g} / \mathrm{g}$.

Cuantificación de las muestras: La central de abastos del sur de Tunja es el lugar de acopio intermedio de productos agrícolas provenientes del departamento (principalmente, de la provincia Centro) y cuyo destino final es la capital del país y la comercialización a minoristas y mayoristas (Municipio de Tunja, 2012). Los municipios que pertenecen a esta provincia representan el $57 \%$ de la producción de papa del departamento, equivalente a 375.612t/anual, con capacidad de abastecimiento permanente de este alimento de alto consumo en la capital del departamento y en el país (Fedepapa, 2014). Este estudio exploratorio permitió verificar la presencia de plomo y de cadmio en el tubérculo fresco con cáscara, comercializado en Tunja y obtenido de diversos municipios, como Boyacá-Boyacá, Siachoque, Ráquira, Toca, Samacá, Chivatá, Ciénega, Ventaquemada, Ramiriquí y Oicatá, principalmente. No se tuvo en cuenta ni variedad, ni zona de cosecha.

Los resultados muestran (Figura 3) que el contenido promedio de plomo y de cadmio oscila entre 0,085 a 0,150 y 0,210 a 0,440mg/kg papa fresca, respectivamente. El Pb es

Tabla 1. Atributos analíticos del método de validación para Cd y Pb.

\begin{tabular}{|l|c|c|}
\hline \multicolumn{1}{|c|}{ Atributo } & Cadmio & Plomo \\
\hline Límite de detección, mg/kg & 0,004 & 0,005 \\
\hline Límite de cuantificación, mg/kg & 0,05 & 0,01 \\
\hline Sensibilidad, nA/mg/kg & $2,0 x E-9$ & $1,0 x E-9$ \\
\hline Exactitud rango alto & $112,6 \%$ & $81,5 \%$ \\
\hline Exactitud rango bajo & $82,4 \%$ & $115,2 \%$ \\
\hline Precisión (coeficiente de variación) & $4,6 \%$ & $3,5 \%$ \\
\hline Incertidumbre (mg/kg) & $\pm 0,005$ & $\pm 0,008$ \\
\hline Nivel de confianza & $94,5 \%$ & $92,0 \%$ \\
\hline
\end{tabular}

Plomo, mg/Kg $\square$ Cadmio,mg/Kg

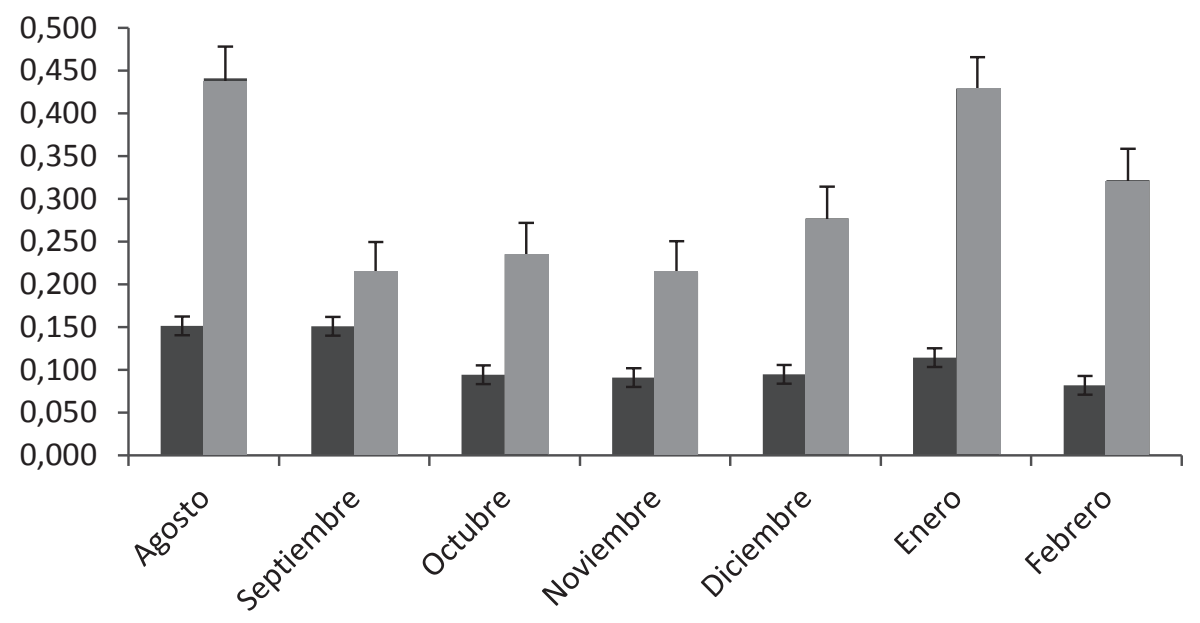

Figura 3. Presencia de cadmio y de plomo en papa fresca, comercializada en la central de abastos del sur de Tunja. 
ligeramente superior al máximo permisible, establecido por el Codex Alimentarius y la Unión Europea, que corresponde a 0,1mg/kg papa fresca con cáscara (Unión Europea, 2014), pero el cadmio sobrepasa estos niveles. Kabata (2000) reporta un contenido de plomo de 0,5 a $3,0 \mathrm{mg} / \mathrm{kg}$ peso seco y de cadmio de 0,041 a $1,05 \mathrm{mg} / \mathrm{kg}$ peso seco en papa. Hortalizas, como lechuga, apio, repollo y brócoli, regadas con aguas del río Bogotá, mostraron niveles altos de cadmio y de plomo y, en algunos casos, superando el límite máximo de la norma de la Unión Europea (Miranda et al. 2008). En Cuba, hortalizas cultivadas en una zona altamente urbanizada de la ciudad de la Habana mostraron concentraciones que sobrepasaron los límites permitidos (Olivares et al. 2013).

El análisis estadístico demostró que no hay diferencia estadística entre el contenido de plomo hallado en la papa durante los siete meses del estudio, caso contrario es el cadmio, en el que el $F$ calculado (65535) fue mayor que el $F$ crítico $(2,84)$. En general, se puede observar que los metales, durante octubre y noviembre, los contenidos están más bajos, mientras que en agosto y enero -para cadmio- y agosto y septiembre -para plomo-, se detectan los valores más altos, lo que puede indicar que en los meses de sequía hay una mayor absorción de metales en los tubérculos.

Teniendo en cuenta que la papa puede ser un bio-acumulador de los excesos de las sustancias presentes en los ecosistemas agrícolas, los resultados presentados pueden indicar la contaminación de suelos o condiciones de $\mathrm{pH}$ favorables para el intercambio de estos minerales (Gebrekidan et al. 2013; Martin et al. 2006). Como fue un estudio exploratorio y aleatorio no se puede demostrar específicamente de dónde provienen estos metales, pero, en forma general, la contaminación del suelo por metales pesados es a menudo consecuencia directa o indirecta de las actividades antropogénicas (Paiva et al. 2009; Gratão et al. 2005; FAO, 2004). En el caso del plomo, incluye los residuos urbanos e industriales, la minería, las industrias metalúrgicas y la polución del aire, debido a la combustión de la gasolina, que contiene aditivos de plomo y por los depósitos de estas partículas del aire en el suelo (Freije, 2015; Demir et al. 2010); en cuanto al cadmio, las fuentes relevantes de este elemento son las actividades industriales, como minería, la fundición de metales no férricos, la producción de compuestos de cadmio, la industria manufacturera de baterías y la galvanoplastia (Kuriakose \& Prasad, 2008). Además, las principales fuentes de emisiones de cadmio en el aire son la combustión de combustibles fósiles, producción de hierro y de acero e incineración de residuos sólidos municipales (Jones et al. 1993). Aunque el centro de Boyacá es una región agrícola por excelencia, no se puede negar el impacto de las fuentes de estos metales, nombradas anteriormente, pero las principales causas parecen ser los pesticidas, los fertilizantes químicos y el riego con aguas residuales. Hasta la década de los 50, las plagas de los diferentes cultivos eran controladas con arseniato de plomo, un plaguicida de amplio espectro, que fue reemplazado por otros insecticidas, como los organofosforados, que son más amables con el medio ambiente, pero que pudieron haber dejado residuos de este metal pesado en el suelo (FAO, 2004). Por otro lado, los fertilizantes fosfatados son otra fuente de metales pesados en la agricultura, pues contienen 25 y $10 \mathrm{mg} / \mathrm{kg}$ de cadmio y de plomo, respectivamente (FAO, 2004; Mortvedt \& Beaton, 1995; Van Assch \& Ciarletta, 1992) y el Cd tiene una alta capacidad para transferirse del suelo a los vegetales (Chang et al. 2014). También, se debe tener en cuenta que, factores como el pH del suelo, el contenido de materia orgánica y el proceso de intercambio iónico, influyen en la disponibilidad y en la transferencia de estos metales. Se recomienda llevar a cabo un estudio más profundo y focalizado, donde se manejen otras variables, como variedad de papa, lugar de cosecha y estación climática. Además, que se tengan en cuenta si el suelo o el agua utilizados en el cultivo presentan metales pesados.

El método de voltametría de onda cuadrada fue válido para la cuantificación de cadmio y de plomo, en uno de los productos básicos de la alimentación de la región cundiboyacense. La papa recolectada en la central de abastos de Tunja presenta cantidades de cadmio y de plomo superiores a los límites permisibles, dados por el Codex Alimentarius y la Unión Europea. Es apropiada la realización de estudios más detallados para la detección de la fuente de los altos contenidos de estos analitos.

Agradecimientos: Los autores agradecen a la Dirección de Investigaciones de la Universidad Pedagógica y Tecnológica de Colombia, por la financiación al proyecto titulado "Determinación de Plomo (II) por Polarografía presente en papa comercializada en la Central de Abastos del Sur de Tunja" SGI 1331. Conflictos de intereses: El manuscrito fue preparado y revisado con la participación de todos los autores, quienes declaramos que no existe-conflicto de intereses que ponga en riesgo la validez de los resultados presentados.

\section{BIBLIOGRAFÍA}

1. ASSOCIATION OFFICIAL ANALYTICAL CHEMISTRY AOAC-.1990. Official Methods of Analysis. 15 Ed. Cap. 9. p.237-250.

2. BARRIENTOS, J.C.; RONDÓN, C.; MELO, S. 2014. Comportamiento de precios de las variedades de papa Parda Pastusa y Diacol Capiro en Colombia (1995-2011). Rev. Col. Cien. Hort. 8(2):272-286.

3. BEHROOZ, J.; NAFICEH, S.; MOHAMMAD, R.O.; ABDOL-AZIM, B.; HOSSEIN, K.; ALIREZA, S. 2009. Simultaneous determination of lead, cadmium, cop- 
per and zinc in infant formula by anodic stripping voltammetry: Iran. J. Pharm. Res. 8(3):159-162.

4. CHANG, C.Y.; YU, H.Y.; CHEN, J.J.; ZHANG, H.H.; LIU, C.P. 2014. Accumulation of heavy metals in leaf vegetables from agricultural soils and associated potential health risks in the Pearl River Delta, South China. Environ. Monit. Assess. 186(3):1547-1560.

5. DEMIR, G.; YIGIT, S.; OZDEMIR, H.; BORUC, G.; SARAL, A. 2010. Elemental concentrations of atmospheric aerosols and the soil samples on the selected playgrounds in Istanbul. J. Residual Sci. Tech. 7(2):123-130.

6. EURACHEM. 2005. Métodos analíticos adecuados a su propósito. Segunda Edición. México. p.7-14.

7. FAO. 2014. Programa Conjunto FAO/OMS sobre Normas Alimentarias Comisión del Codex Alimentarius 37. Período de sesiones 14-18 de julio de 2014. Ginebra (Suiza).

8. FAO. 2004. Código de prácticas para la prevención y reducción de la presencia de plomo en los Alimentos CAC/RCP 56-2004. Comisión del Codex Alimentarius. Disponible desde Internet en: http://www.codexalimentarius.org/input/download/standards/10099/ CXP_056s.pdf (con acceso 04/12/2015).

9. FEDEPAPA. 2014. Cultivo de la papa. Disponible desde Internet en: http://www.fedepapa.com/?page id $=401$ (con acceso14/02/2015).

10. FREIJE, A.M. 2015. Heavy metal, trace element and petroleum hydrocarbon pollution in the Arabian Gulf: Review. J. Assoc. Arab. Univ. Bas. Appl. Sci. 17:90-100.

11. GEBREKIDAN, A.; WELDEGEBRIEL, Y.; HADERA, A.; BRUGGEN, B. V. 2013. Toxicological assessment of heavy metals accumulated in vegetables and fruits grown in Ginfel river near Sheba Tannery, Tigray, Northern Ethiopia. Ecotox. Environ. Safe. 95:171-178.

12. GRATÃO, P.L.; POLLE, A.; LEA, P.J.; AZEVEDO, R.A. 2005. Making the life of heavy metal stressed plants a little easier. Funct. Plant Biol. 32:481-494.

13. GUZINSKI, M.; LISAK, G.; KUPIS, J.; JASINSKI, A.; BOCHENSKA, M. 2013. Lead (II)-selective ionophores for ion-selective electrodes: A review. Anal. Chim. Acta. 791:1-12.

14. HUANG, Z.; PAN, X.D.; WU, P.G.; HAN, J.L.; CHEN, Q. 2014. Heavy metals in vegetables and the health risk to population in Zhejiang, China. Food Control. 36:248-252.
15. INSTITUTO INTERAMERICANO DE COOPERACIÓN PARA LA AGRICULTURA -IICA-. 1999. Ministerio de Agricultura y Desarrollo Rural. IICA. Acuerdo de competitividad cadena agroalimentaria de la papa. Disponible desde Internet en: http://bibliotecadigital.agronet.gov.co/jspui/bitstre am/11348/5559/1/20051130134357_acuerdopapa\%201999\%20si.pdf (con acceso 5/12/2014).

16. ISHA, A.; YUSOF, N.A.; ABDUL MALIK, M.; HAMDAN, H. 2007. Simultaneous spectrophotometric determination of $\mathrm{Pb}(\mathrm{II})$ and $\mathrm{Cd}(\mathrm{II})$ using artificial neural networks. J. Phys. Sci. 18:1-10.

17. JAKUMNEE, J.; SUTEERAPATARANON, S.; VANEESORN, Y.; GRUDPAN, K. 2001. Determination of cadmium, copper, lead and zinc by flow voltammetric analysis. J. Anal. Sci. Suplem. 17:399-401.

18. JONES, R.; LAPP, T.; WALLACE, D. 1993. Locating and estimating air emissions from sources of cadmium and cadmium compounds. Prepared by Midwest Research Institute for the U.S. Environmental Protection Agency, Office of Air and Radiation, Report. EPA:453/R: 93-040.

19. KABATA, A. 2000. Trace elements in soil and plants. Third Edition. CRC Press. Boca Ratón, USA. 413p.

20. KLAMTET, J.; SANGUTHAI, S.; SRIPRANG, S. 2007. Determination of lead in aqueous samples using a flow injection analysis system with on-line preconcentration and spectrophotometric detection: NU. Science J. 4:122-131.

21. KURIAKOSE, S.V.; PRASAD, M.N.V. 2008. Cadmium as an environmental contaminant: Consequences to plant and human health. En: Prasad, M.N.V. (ed.) Trace elements as ontaminants and nutrients: Consequences in ecosystems and human health. John Wiley \& Sons, Inc. p.373-412.

22. MADERO, A.; MARRUGO, J. 2011. Detección de metales pesados en bovinos, en los valles de los ríos Sinú y San Jorge, departamento de Córdoba, Colombia. Rev. MVZ. 16:2391-2401.

23. MARTIN, D.; VOLLENWEIDER, P.; BUTTLER, A.; GÜNTHARDT-GOER, M.S. 2006. Bioindication of heavy metal contamination in vegetable gardens. For. Snow Landsc. Res. 80:169-180.

24. MHAMMEDI, M.A.; ACHAK, M.; BAKASSE, M. 2010. Square wave voltammetry for analytical determination of cadmium in natural water using $\mathrm{Ca}_{10}\left(\mathrm{PO}_{4}\right)_{6}(\mathrm{OH})_{2-}$ 
modified platinum electrode. Amer. J. Anal. Chem. 1(3):150-158.

25. MINISTERIO DE SALUD. 2011. Guía de validación de métodos analíticos. Disponible desde Internet en: http://www.ministeriodesalud.go.cr/index.php/tramites-ms/registro-de-productos-de-interes-sanitario/ medicamentos-1/documentos-de-interes-3/guiasde-registro-medicamentos/2472-guia-de-validacionde-metodos-analiticos/file (con acceso 15/12/2014).

26. MINISTERIO DE SALUD Y PROTECCIÓN SOCIAL. 2013. Resolución 4506 de 2013. p.6,7.

27. MIRANDA, D.; CARRANZA, C.; ROJAS, C.A.; JEREZ, C.M.; FISCHER, G.; ZURITA, J. 2008. Acumulación de metales pesados en el suelo y plantas de cuatro cultivos hortícolas, regados con aguas del río Bogotá. Rev. Col. Cienc. Hort. 2(2):180-191.

28. MORTVEDT, J.J.; BEATON, J.D. 1995. Heavy metal and radionuclide contaminants in phosphate fertilizers. In: Tiessen H, (ed.). Phosphorus in the global environment: transfer, cycles and management. New York: Wiley. p.93-106.

29. MUNICIPIO DE TUNJA. 2012-2015. Plan de Desarrollo "Hechos de Verdad". Tunja, Boyacá. Colombia.

30. OLIVARES, S.; GARCÍA, D.; LIMA, L.; SABORIT, I.; LLIZO, A.; PÉREZ, P. 2013. Niveles de cadmio, plomo, cobre y zinc en hortalizas cultivadas en una zona altamente urbanizada de la ciudad de la Habana Cuba. Rev. Int. Contam. Ambient. 29(4):285-294.

31. PAIVA, L.B.; OLIVEIRA, J.G.; AZEVEDO, R.A.; RIBEIRO, D.R.; SILVA, M.G.; VITÓRIA, A.P. 2009. Ecophysiological responses of water hyacinth exposed to $\mathrm{Cr}^{3+}$ and $\mathrm{Cr}^{6+}$. Environ. Exp. Bot. 65:403-409.

32. ROSOLINA, S.M.; CHAMBERS, J.Q.; LEE, C.W.; XUE, Z.L. 2015. Direct determination of cadmium and lead in pharmaceutical ingredients using anodic stripping voltammetry in aqueous and DMSO/water solutions. Anal. Chim. Acta. 893:25-33.

33. RUTYNA, I.; KOROLCZUK, M. 2014. Determination of lead and cadmium by anodic stripping voltammetr- yat bismuth film electrodes following double deposition andstripping steps. Sensor Acuat B: Chem. 204:136-141.

34. SEGURA, J.M. 2003. Polarografía moderna una herramienta indispensable en el análisis de contaminantes a niveles de e-trazas y ultra trazas. Química e Industria. 541:18-28.

35. UNIÓN EUROPEA. 2014. Contenidos máximos de metales pesados en productos alimenticios. Disponible desde Internet en: http://plaguicidas.comercio.es/ MetalPesa.pdf (con acceso 15/01/2014).

36. VANASSCH, F.J.; CIARLETTA, E.P. 1992. Cadmium in the environment: Levels, trends and critical pathways. In: Edited Proceedings Seventh International Cadmium Conference-New Orleans, Cadmium Association, London, Cadmium Council, Reston VA, International Lead Zinc Research Organization, Research Triangle Park, NC.

37. WANG, Y.; CHEN, H.; TANG, J., YE, G.; GE, H.; HU, X. 2015. Preparation of magnetic metal organic frameworks adsorbent modified with mercapto groups for the extraction and analysis of lead in food samples by flame atomic absorption spectrometry. Food Chem. 181:191-197.

38. WANG, Y.; HAN, J.; LIU, Y.; WANG, L.; NI, L.; TANG, X. 2016. Recyclable non-ligand dual cloud point extraction method for determination of lead in food samples. Food Chem. 190:1130-1136.

39. YAVUZ, E.; TOKALIOGLU, S.; SAHAN, H.; PATAT, S. 2016. Nanosized spongelike $\mathrm{Mn} 3 \mathrm{O} 4$ as an adsorbent for preconcentration by vortex assisted solid phase extraction of copper and lead in various food and herb samples. Food Chem. 194:463-469.

40. YUCRA, S.; GASCO, M.; RUBIO, J.; GONZÁLES, G. 2008. Exposición ocupacional a plomo y pesticidas organofosforados: efectos sobre la salud reproductiva masculina. Rev. Perú. Med. Exp. Salud Pública. 25(4):394-402.

Recibido: Octubre 21 de 2015

Aceptado: Abril 29 de 2016

\section{Cómo citar:}

Moreno Mariño, Y.L.; García Colmenares, J.M.; Chaparro Acuña, S.P. 2016. Cuantificación voltamétrica de plomo y cadmio en papa fresca. Rev. U.D.C.A Act. \& Div. Cient. 19(1): 97-104. 